\title{
Gender differences in aortic valve replacement: is surgical aortic valve replacement riskier and transcatheter aortic valve replacement safer in women than in men?
}

\author{
Maria Giulia Caponcello ${ }^{1,2}$, Lucia M. Banderas ${ }^{1}$, Carmen Ferrero ${ }^{1}$, Carsten Bramlage ${ }^{2}$, \\ Martin Thoenes ${ }^{1,3}$, Peter Bramlage ${ }^{1,2}$ \\ ${ }^{1}$ Departamento Farmacia y Tecnología Farmacéutica, Universidad de Sevilla, Sevilla, Spain; ${ }^{2}$ Institute for Pharmacology and Preventive Medicine, \\ Cloppenburg, Germany; ${ }^{3}$ Leman Research Institute, Switzerland \\ Contributions: (I) Conception and design: MG Caponcello, LM Banderas, C Ferrero; (II) Administrative support: LM Banderas, C Ferrero, P \\ Bramlage; (III) Provision of study materials or patients: C Bramlage, M Thoenes, P Bramlage; (IV) Collection and assembly of data: MG Caponcello, \\ M Thoenes, P Bramlage; (V) Data analysis and interpretation: MG Caponcello, M Thoenes, P Bramlage; (VI) Manuscript writing: All authors; (VII) \\ Final approval of manuscript: All authors. \\ Correspondence to: Prof. Peter Bramlage. Institute for Pharmacology and Preventive Medicine, Bahnhofstrasse 20, 49661 Cloppenburg, Germany. \\ Email: peter.bramlage@ippmed.de.
}

\begin{abstract}
Aortic stenosis (AS) is a progressive and degenerative disease that necessitates valve replacement through either surgical aortic valve replacement (SAVR) or transcatheter aortic valve replacement (TAVR). Various studies have shown that, unlike for TAVR, SAVR is associated with an elevated risk for women as compared to men. The aim of this review is to better understand the risks and their possible causes, associated with the use of both TAVR and SAVR in female patients. Our systematic review included studies published between 2012 and 2020, identified through specific searches of PubMed. Compatibility of publications, determined by the use of pre-defined inclusion/exclusion criteria, resulted in 15 articles being used in our review. Overall, more men than women undergo SAVR, but our findings confirmed that SAVR is associated with worse outcomes in women in the short-term. Reasons for a higher 30-day mortality postSAVR in women include an increased age, higher in-hospital mortality and, possibly baseline comorbidities and anatomical differences. There was no difference observed in 30-day mortality between men and women undergoing TAVR. Female patients appear to have a better longer-term survival post-TAVR than their male counterparts. Understanding the reasons why women have worse outcomes post-SAVR is essential for ensuring appropriate treatment selection for patients with AS, as well as for achieving the best possible longterm and safety outcomes for these patients.
\end{abstract}

Keywords: Transcatheter aortic valve replacement (TAVR); surgical aortic valve replacement (SAVR); women; gender disparities

Submitted Jan 29, 2020. Accepted for publication May 08, 2020.

doi: $10.21037 /$ jtd-20-700

View this article at: http://dx.doi.org/10.21037/jtd-20-700

\section{Introduction}

Aortic stenosis (AS) is the most common form of valvular abnormality in the developed world and accounts for $>40 \%$ of patients with native valvular disease with an approximately equal prevalence in males and females (1). $\mathrm{AS}$ is both a progressive and degenerative disease that necessitates valve replacement to prevent irreversible haemodynamic changes and damage to the heart (2). Interventions for AS, which are usually chosen according to physician expertise and patient characteristics, include surgical aortic valve replacement (SAVR) or transcatheter aortic valve replacement (TAVR), which can be carried 
out via various access routes including the transfemoral (TF), transapical (TA), transaortic (TAo), transcarotid, transsubclavian and transcaval access routes (3-6).

A number of studies have suggested that the SAVR procedure might represent a greater risk for women than for men, while the TAVR procedure presents a lower risk in women (1,7-9). Generally, these sex disparities have not been the focus of studies and in cardiovascular $(\mathrm{CV})$ device trials, the sex distribution of participants is largely skewed by disease prevalence, with men constituting $70-80 \%$ of study participants, resulting in small sample sizes of women and low statistical power for identifying meaningful sexrelated outcomes (10). Furthermore, the last two major studies were not designed to address the impact of sex on valve replacement $(11,12)$. As a result, the majority of relevant differences in sex-specific outcomes are uncovered through post-hoc analyses, calling into question the reliability of the evidence (10). Fortunately, cardiac/valvular device implantation trials in patients with AS do not show gender bias due to a comparable prevalence of disease in male and female patients $(13,14)$. As a result, we sought to determine whether there are significant differences between women and men with regards to the safety and effectiveness of both SAVR and TAVR.

\section{Methods}

A search was conducted of the PubMed database for articles, with no language restrictions, published since 2012 and up until April 03 2020. The search terms included "(sex OR gender) AND (differences OR comparison) AND aortic stenosis AND (transcatheter OR surgical) AND (implantation OR replacement) AND valve". Filters applied were: Clinical Study, Clinical Trial, Clinical Trial, Phase III, Clinical Trial, Phase IV, Comparative Study, Meta-Analysis, Multicenter Study, Observational Study, Randomized Controlled Trial. Overall, this search criteria yielded 117 initial articles where we screened the abstract for relevancy.

The inclusion criteria for the articles in our analysis were: (I) the inclusion of patients with severe aortic valve stenosis undergoing AVR; (II) studies regarding a singlegroup cohort or a controlled comparison between TAVR and SAVR through random or non-random allocation and (III) available data on at least short-term (30-day or inhospital) or 1-year all-cause mortality (Figure 1).

Additional studies were included by searching the bibliographies of the articles and meta-analyses identified above. Studies were included if they examined the clinical outcome in patients with AS who underwent TAVR or SAVR and if they reported clinical outcomes of interest in women or in women versus men in agreement with the above selection criteria. Again, no language restrictions were applied to these articles. An overview of the included articles, their study designs and principle findings are provided in Tables 1,2,3.

\section{Results}

\section{Trends in cardiovascular disease (CVD) in women}

CVD continues to be the leading cause of death among women in the United States (US), accounting for one of every three female deaths (26). Despite this fact, a recent nationwide survey from the Women's Heart Alliance showed that almost half of women were unaware that CVD is the most frequent cause of death among their sex and only $39 \%$ of primary care physicians considered CVD as one of the top concerns (8). Of these CVDs, AS accounts for $>40 \%$ of patients with native valvular disease and it occurs with approximately equal prevalence in males and females (1). The prevalence of severe AS that requires immediate intervention, with either SAVR or TAVR performed through various different access routes, is increasing as the size of the elderly population increases (3).

\section{Differences in referrals for male and female patients with $A S$}

One important factor that impacts on patient treatment is specialist referral. Data from administrative claims databases in the US shows that significantly fewer women with AS were seen by specialists and that these patients underwent fewer diagnostic tests. This resulted in approximately half the number of women being treated with SAVR compared to men $(15,27)$. It was suggested that this lower referral rate was likely the result of women having more unfavourable pre-operative baseline characteristics (15).

\section{Differences in risk profiles for male and female patients with $A S$}

Studies have shown that the risk profile and baseline conditions for women and men undergoing the SAVR procedure is different $(15,16)$. Compared with men, women are typically older and have more non-atherosclerotic comorbid conditions, such as hypertension, diabetes mellitus (DM), obstructive pulmonary disease, atrial 


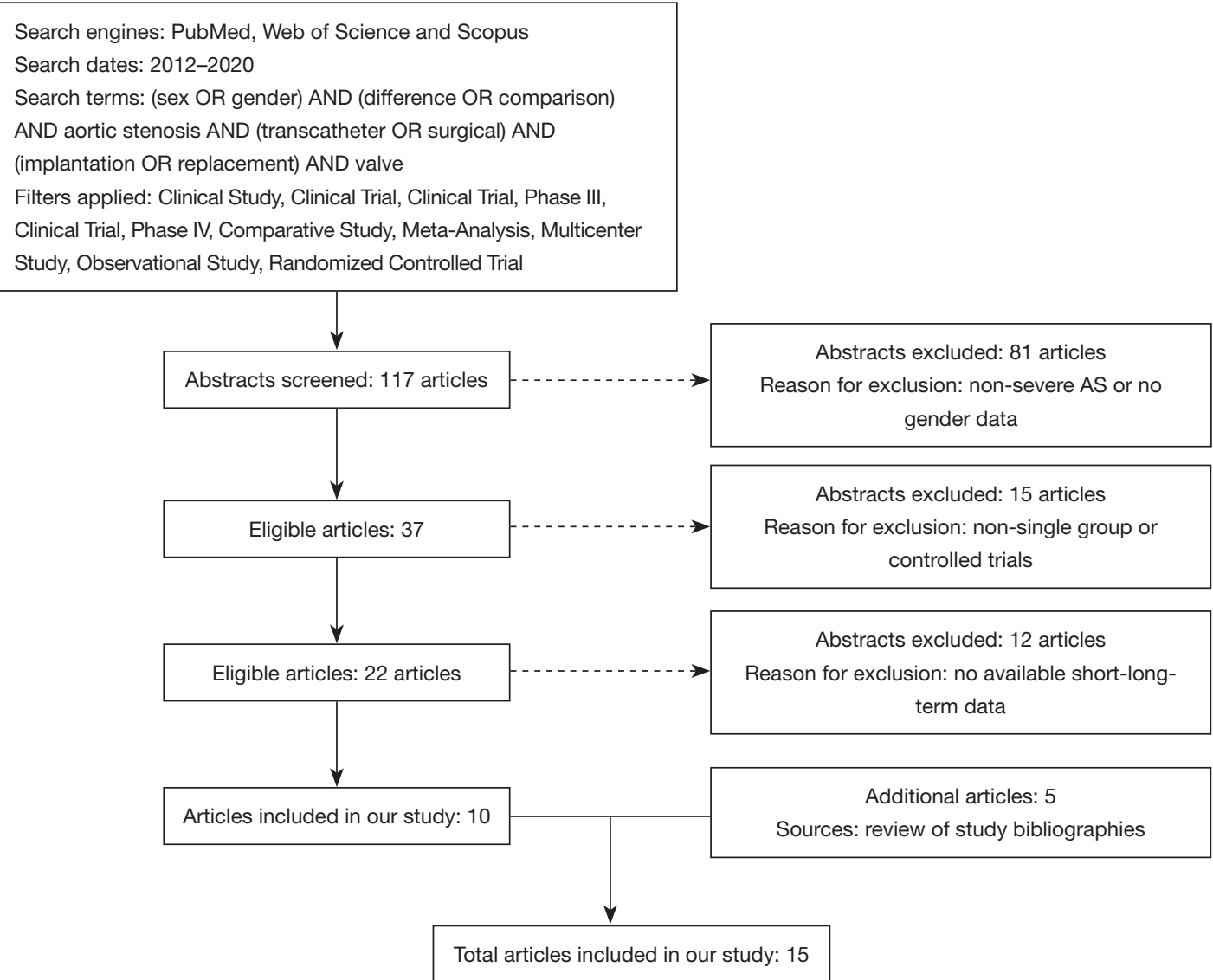

Figure 1 Overview of methodology for identifying publications included in this study.

fibrillation/flutter $(\mathrm{AF})$ and anaemia, but a lower prevalence of coronary and peripheral arterial disease (PAD), renal disease, cerebrovascular disease and prior sternotomies $(15,16)$. This supports the findings of other studies that SAVR is generally used in lower risk patient groups and may explain why this procedure is more commonly used in men (28). The increased age and higher numbers of comorbidities tend to push these female patients into the higher risk groups.

\section{Anatomical differences in men and women with AS and their impact on treatments}

One of the largest registries to date-the Italian Observational Multicentre Registry-found, that lower bodyweight and serum albumin levels in women, and parallel cardiac structures that are smaller than those in men, could result in more technically demanding SAVR procedures in women. These differences in physiology, disease pathology, presentation and management may contribute to gender-specific differences in clinical outcomes following valve surgery (8).

Women with AS demonstrate specific clinical, anatomical and pathophysiological features in myocardial adaptation to AS both before and after valve replacement. Women exhibit more concentric remodelling and subsequent concentric LV hypertrophy (LVH), with higher relative wall thickness and smaller end-diastolic diameter than seen in men, who are frequently found to have a higher prevalence of eccentric hypertrophy in this setting (13).

Furthermore, sex hormones and oestrogen receptors and their signalling pathways, which can remain active even after menopause, may also play a role in sex-specific $\mathrm{LV}$ remodelling, because studies in animal models have shown that oestrogen binding can modulate growth-factor signalling, modulating myocyte necrosis and apoptosis (29).

While these gender-specific differences may impact on gender-specific mortality associated with SAVR, further 


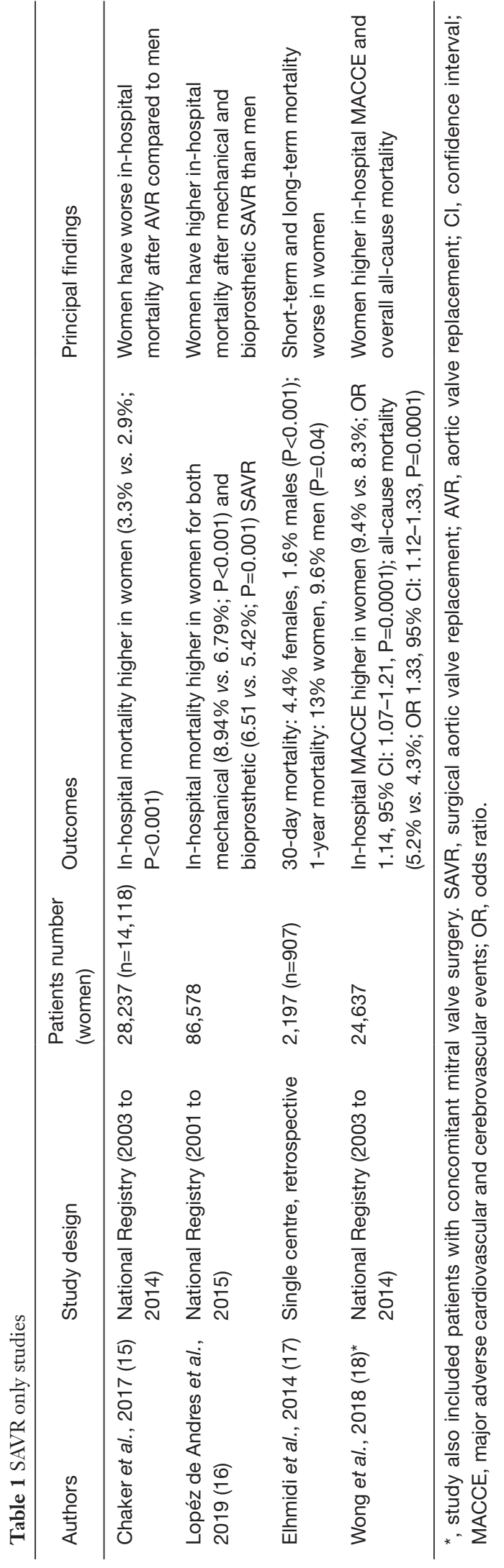

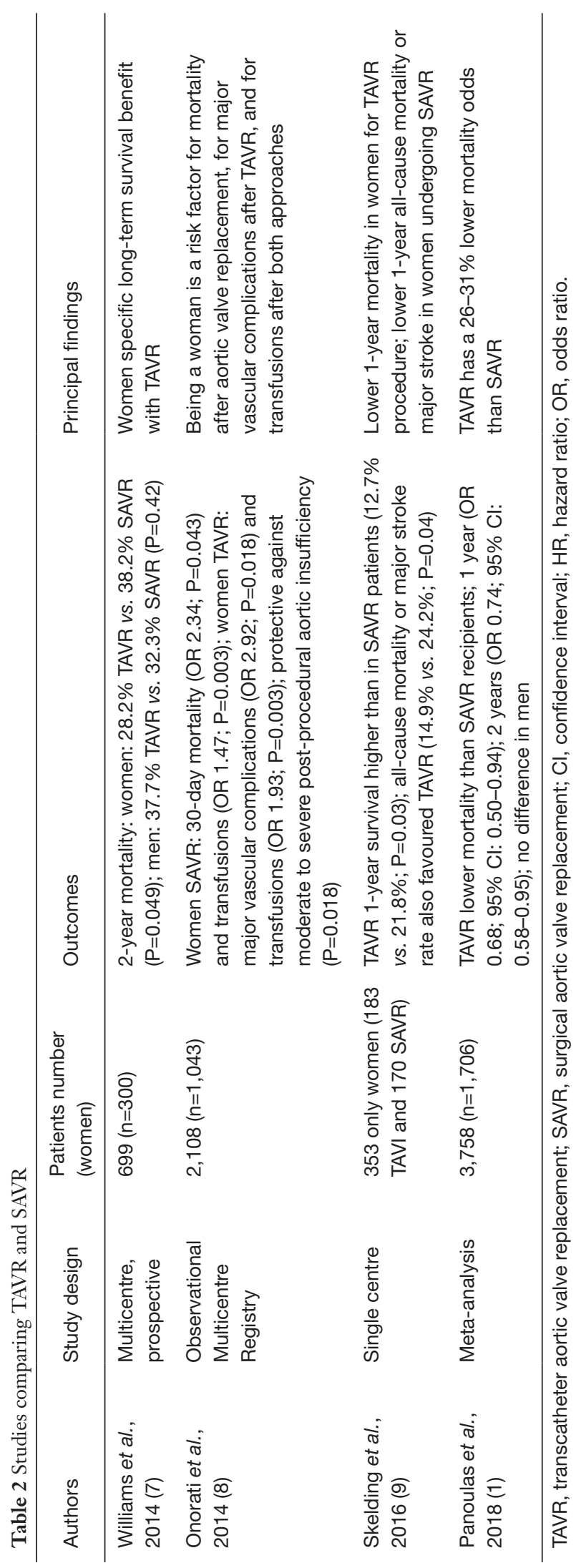


Table 3 Women TAVR studies

\begin{tabular}{|c|c|c|c|c|}
\hline Authors & Study design & $\begin{array}{l}\text { Patients number } \\
\text { (women) }\end{array}$ & Outcomes & Principal findings \\
\hline $\begin{array}{l}\text { Hayashida et al., } \\
2012 \text { (19) }\end{array}$ & $\begin{array}{l}\text { Single } \\
\text { centre, } \\
\text { prospective }\end{array}$ & $260(n=131)$ & $\begin{array}{l}\text { 30-day mortality: } 12.2 \% \text { women, } 17.8 \% \text { men } \\
(P=0.207) ; 1 \text {-year mortality: HR 1.62, } 95 \% \mathrm{Cl} \text { : } \\
1.03-2.53, P=0.037\end{array}$ & $\begin{array}{l}\text { Similar short-term but better } \\
\text { 1-year mortality in women }\end{array}$ \\
\hline $\begin{array}{l}\text { Humphries et al., } \\
2012 \text { (20) }\end{array}$ & $\begin{array}{l}\text { Multicentre, } \\
\text { retrospective }\end{array}$ & $641(n=329)$ & $\begin{array}{l}\text { 30-day mortality: } 6.5 \% \text { women, } 11.2 \% \text { men } \\
(P=0.05)\end{array}$ & $\begin{array}{l}\text { Better short-term mortality in } \\
\text { women }\end{array}$ \\
\hline $\begin{array}{l}\text { Saad et al., } \\
2018 \text { (22) }\end{array}$ & $\begin{array}{l}\text { Meta- } \\
\text { analysis }\end{array}$ & $47,188(n=23,303)$ & $\begin{array}{l}\text { Women lower all-cause mortality at } 1 \text { year (risk } \\
\text { ratio: } 0.85 ; 95 \% \mathrm{Cl} \text { : } 0.79-0.91 ; \mathrm{P}<0.001 \text { ) and } \\
\text { longest-available follow-up (mean } 3.28 \pm 1.04 \text { years; } \\
\text { risk ratio: } 0.86 \text {; } 95 \% \mathrm{Cl}: 0.81-0.92 ; \mathrm{P}<0.001 \text { ) }\end{array}$ & $\begin{array}{l}\text { Women higher risk of } \\
\text { complications, but better } \\
\text { long-term survival after TAVR }\end{array}$ \\
\hline $\begin{array}{l}\text { Chieffo et al., } \\
2016 \text { (24) }\end{array}$ & $\begin{array}{l}\text { WIN-TAVI } \\
\text { registry }\end{array}$ & 1,019 only women & 30-day VARC-2 composite safety endpoint ${ }^{\star} 14.0 \%$ & $\begin{array}{l}\text { Low incidence of mortality } \\
\text { and stroke }\end{array}$ \\
\hline $\begin{array}{l}\text { Chieffo et al., } \\
2018 \text { (25) }\end{array}$ & $\begin{array}{l}\text { WIN-TAVI } \\
\text { registry }\end{array}$ & 1,019 only women & 1-year VARC-2 composite efficacy endpoint ${ }^{\star \star} 16.5 \%$ & $\begin{array}{l}\text { Low incidence of mortality } \\
\text { and stroke }\end{array}$ \\
\hline
\end{tabular}

*, composite of mortality, stroke, major vascular complication, life-threatening bleeding, stage 2 or 3 acute kidney injury, coronary artery obstruction, or repeat procedure for valve-related dysfunction; ${ }^{* *}$, composite of mortality, stroke, myocardial infarction, hospitalization for valve-related symptoms or heart failure or valve-related dysfunction beyond 30 days. TAVR, transcatheter aortic valve replacement; Cl, confidence interval; HR, hazard ratio; OR, odds ratio; SAVR, surgical aortic valve replacement.

research is needed to better understand the exact cause behind this.

\section{The use of SAVR and TAVR for the treatment of AS in female patients}

Although both SAVR and TAVR provide beneficial outcomes for patients with AS, the increased risk associated with SAVR in female patients, compared to male patients, has recently come under question (1,7-9). SAVR has been available since the 1960s and, for the majority of patients, reduces mortality, provides symptom relief and increases quality-of-life (28). Various comorbidities, however, represent a relevant increase in risk because AS usually appears at an advanced age. Surgery for AS in women is usually more technically demanding due to smaller annuli size, increased need for aortic enlargement and complications related to cardiopulmonary bypass. In addition, women tend to be older and in a more advanced stage of the disease with greater frailty at the time of surgical referral (30).
The alternative approach to SAVR is the TAVR procedure. TAVR also provides an option for patients who are deemed 'inoperable', such as those with porcelain aorta or a hostile chest from previous radiotherapy where surgery is not technically possible. As a result, TAVR provides a solution for the substantial proportion of patients who would previously have been untreated despite their poor prognosis. Procedural success with TAVR is comparable between women and men $(14,31)$, but studies have shown that TAVR is associated with a lower risk in terms of 30 -day and 1-year mortality in women than in men (1,7-9). Furthermore, the TAVR procedure is not associated with any differences in terms of post-procedural frailty or quality-of-life between women and men (14).

\section{SAVR: sex-related differences in treatment outcomes}

SAVR was the first procedure that provided definitive treatment for AS, and for decades it represented the gold standard treatment for this disease (32). However, the surgical procedure excludes a considerable portion of 
the patients affected by AS-approximately one-third of elderly patients with severe, symptomatic AS are denied surgery by the attending practitioner-due to increased age, a left ventricular ejection fraction (LVEF) $<50 \%$ and comorbidities (33). In addition, various studies have reported worse outcomes for women with SAVR compared to men. Conversely, however, women appear to have a better outcome with the more recently introduced TAVR approach than men, and the number of studies showing this trend is increasing (1,7-9).

\section{SAVR: in-bospital and 30-day mortality}

Chaker et al. reported a consistently higher unadjusted and adjusted in-hospital mortality (IHM) rate in women postSAVR compared to men. Their study suggested that women had more vascular complications and blood transfusions than men and were more likely to be discharged to a skilled nursing facility, nursing home, or intermediate care centre (15). A higher IHM in women was also registered in the 2019 study from Lopéz-de-Andrés et al. where they stated that females had significantly higher IHM irrespective of all the comorbid conditions analysed (16). These results differ from some older studies that, after adjustment of the results, did not show a significant difference in IHM and suggest that there is no greater than a 2.5 -fold increase in risk for females compared with males undergoing AVR. Female gender, however, may impose an increased risk for cardiac morbidity after AVR (34).

In the Elhmidi et al. study, the 30-day mortality endpoint showed that women exhibited a higher 30-day mortality post-SAVR when compared to male patients and that female gender was considered an independent factor for 30-day mortality after adjustment for baseline characteristics. Interestingly, after 30 days, the only independent risk factor for later mortality in their study was age (17).

\section{TAVR: gender-specific data on treatment risk in women}

Interventional cardiology has been revolutionised by TAVR, which is now established as the standard treatment for severe AS in patients at high-risk for SAVR (35). Such are the benefits of TAVR that the procedure is now being increasingly performed in intermediate- and low-risk patients with AS (36,37). Several studies have focused their attention on the growing evidence that women benefit from a better outcome with this procedure when compared to men, especially in the long-term. This is of great interest, not only because women represent $50 \%$ of the eligible patients for TAVR but also because this procedure appears to be more cost-effective in women due to their longer life expectancy (20).

According to O'Connor et al. there is a significant difference in baseline clinical demographics of male and female patients undergoing TAVR. In particular, men had a higher number of risk factors than women [including DM, previous myocardial infarction (MI), previous percutaneous coronary intervention (PCI) and poor LV systolic function (LVEF <30\%)]. Conversely, women were older, had higher transvalvular gradients and high pulmonary artery pressures, higher LVEF and smaller annular sizes (21). This depiction of the baseline conditions of patients undergoing TAVR was consistent in the other studies analysed in our systematic review.

This is also supported by the PARTNER trial, published in 2010, which showed that women who undergo TAVR are typically older and deemed to be more frail than male counterparts. Conversely, however, women tend to have a higher LVEF and reduced frequency of coronary artery disease (CAD) and prior coronary revascularisation compared to men (38).

\section{TAVR: in-bospital and 30-day mortality}

Chandrasekhar et al. showed a higher risk of in-hospital vascular complications in women undergoing TAVR for AS but concluded that there were no differences in IHM between the sexes (23). One of the main trial endpoints of the treatment of AS is 30-day mortality. Interestingly, although men and women show significantly different risk profiles and baseline conditions, various studies have shown a similar rate of 30-day mortality for both sexes postTAVR. These studies include the registry study conducted by Hayashida et al., where no significant difference was observed between the sexes (19); an observation that was later supported by Saad et al. (22). The OBSERVANT registry found no sex-related differences in 30-day mortality following TAVR, but they did identify increased rates of vascular damage and the need for blood transfusions in women. A propensity matched sub-study of this registry found comparable IHM rates in females undergoing SAVR and TAVR with a higher transfusion rate, more renal and heart failure, and higher transvalvular gradients in females following SAVR and more post-procedural aortic regurgitation, a higher stroke rate, more vascular complications, and a higher permanent pacemaker insertion 
and PCI rate in women undergoing TAVR (8). While O'Connor et al. reported no differences in 30-day mortality between male and female patients, their study also showed that women had higher rates of major vascular, bleeding and stroke events (21). This result is partially supported by the finding of Humphries et al. where women showed more major/life-threatening bleeds, needed more blood transfusions and had more vascular complications, but overall women seemed to have a better survival rate at 30 days (20).

Overall, the likelihood of poor outcomes of TAVR in female patients with AS is relatively low. The first ever all-female TAVR registry was the WIN-TAVI registry (Women's INternational Transcatheter Aortic Valve Implantation). It included 1,019 patients enrolled between January 2013 and December 2015. The primary endpoint was the Valve Academic Research Consortium (VARC)2 early safety endpoint at 30 days (composite of mortality, stroke, major vascular complication, life-threatening bleeding, stage 2 or 3 acute kidney injury, coronary artery obstruction, or repeat procedure for valve-related dysfunction). Chieffo et al. registered a 30-day VARC-2 composite safety endpoint approximately of $14.0 \%$ of their all-female study population, with a low incidence of early mortality and stroke (24).

\section{TAVR: 1-year mortality}

Three studies focussed on 1-year mortality post-TAVR in patients with AS as one of their study endpoints $(19,22,23)$. Both Chandrasekhar et al. and Hayashida et al. identified a higher 1-year survival rate for women and these studies suggested that this could be explained by women's longer life expectancy and that it was also influenced by a lower rate of baseline comorbidities $(19,23)$. Saad et al. reported a lower 1-year mortality for women but noted a potential increased risk of stroke (22).

Skelding et al. conducted an evaluation of TAVR with a self-expanding valve versus SAVR in women through a randomised trial (9). The study objective was to compare outcomes in women after SAVR. Overall 353 women were treated, and 183 women received TAVR and 170 SAVR. Baseline characteristics and the predicted risk of the two groups were comparable, although the frequency of DM was lower in patients undergoing TAVR $33.3 \%$ vs. $45.3 \%$; $\mathrm{P}=0.02)$. TAVR-treated patients experienced a statistically significant 1-year survival advantage compared with SAVR patients $(12.7 \%$ vs. $21.8 \%$; $\mathrm{P}=0.03)$. The composite all- cause mortality or major stroke rate also favoured TAVR (14.9\% vs. $24.2 \% ; \mathrm{P}=0.04)$. The study concluded that female TAVR patients had lower 1-year mortality and lower 1-year all-cause mortality or major stroke compared with women undergoing SAVR, with both cohorts experiencing improved quality-of-life.

The 1-year outcome of the WIN-TAVI registry revealed a VARC-2 composite efficacy endpoint (composite of mortality, stroke, myocardial infarction, hospitalization for valve-related symptoms or heart failure or valve-related dysfunction beyond 30 days) of $16.5 \%$ in female patients undergoing TAVR, with a low incidence of 1 -year mortality and stroke (25).

\section{TAVR: longer-term outcomes}

Williams et al. carried out a retrospective sub-analysis of high-risk, symptomatic AS patients in the PARTNER trial and the results showed that female subjects had lower late mortality with TAVR compared with SAVR. The study outlined the differences in baseline characteristics for men and women, with women being older and having fewer important comorbidities (7). At 2-year of follow up, allcause mortality in the female TAVR group was significantly lower than in the female SAVR group [hazard ratio (HR) 0.67], driven by a very significant reduction in women undergoing TF-TAVR, and no mortality benefit in those with a TA access route. Furthermore, there was no survival advantage in men undergoing TAVR compared with SAVR at 2 years.

Panoulas et al. performed a meta-analysis of the genderspecific subgroup results of randomised controlled trials that evaluated the survival of patients with severe AS treated with TAVR versus SAVR. Four randomised clinical trials met the criteria, totalling 3,758 patients (comprising 1,706 women and 2,052 men). Female TAVR recipients had a significantly lower mortality than SAVR recipients at 1-year [odds ratio (OR) $0.68 ; 95 \%$ CI: $0.50-0.94$ ] and at 2-year (OR 0.74; 95\% CI: 0.58-0.95). Amongst males there was no difference in mortality between TAVR and SAVR at 1-year (OR 1.09; 95\% CI: $0.86-1.39$ ) or 2-year (OR 1.05; 95\% CI: $0.85-1.3)$. The difference in treatment effect between genders was significant at both 1 -year $\left(\mathrm{P}_{\text {interaction }}=0.02\right)$ and 2 -year $\left(\mathrm{P}_{\text {interaction }}=0.04\right)$. In women, TAVR has a $26-31 \%$ lower mortality odds than SAVR. In men, there is no difference in mortality between TAVR and SAVR (1). These results indicate that for women TAVR results in significantly better survival than SAVR. Interestingly, men 
do not show this same pattern, and the difference between the genders is statistically significant.

\section{Rationale for the benefit of TAVR over SAVR in women}

The reasons for this possible female-sex-related survival benefit in patients with AS undergoing TAVR are still not entirely clear. Some possible reasons cited by Panoulas et al. include that there is a tendency in women for TAVR (in comparison to SAVR) to result in lower peri-procedural mortality, lower bleeding rates and acute kidney injury (AKI), better LV function recovery and larger postprocedural AVA, may more than counteract the higher rate of moderate paravalvular leak and vascular complications. This 'TAVR survival benefit' was not observed in males, who in general have higher comorbidity burden, including cardiovascular and respiratory disease, alongside increased paravalvular aortic regurgitation (1).

\section{Conclusions}

Our literature review suggests that SAVR is associated with an increased risk of 30-day mortality in women compared to men, which is possibly due to increased age, comorbidities and higher in-hospital mortality. Anatomical differences between women and men with AS may also play a role in the increased risk associated with SAVR, but further research is needed to confirm this. With this information, women with adverse anatomical risks for SAVR can be more readily identified and treated with TAVR to ensure optimal patient safety and outcomes. Conversely, there is no gender bias associated with TAVR in terms of procedural success or post-procedural mortality, frailty or quality-of-life.

\section{Acknowledgments}

Funding: None.

\section{Footnote}

Conflicts of Interest: All authors have completed the ICMJE uniform disclosure form (available at http://dx.doi. org/10.21037/jtd-20-700). MT is an employee of Edwards Lifesciences. PB reports grants and other from Edwards Lifesciences, outside the submitted work. The authors have no other conflicts of interest to declare.

Ethical Statement: The authors are accountable for all aspects of the work in ensuring that questions related to the accuracy or integrity of any part of the work are appropriately investigated and resolved.

Open Access Statement: This is an Open Access article distributed in accordance with the Creative Commons Attribution-NonCommercial-NoDerivs 4.0 International License (CC BY-NC-ND 4.0), which permits the noncommercial replication and distribution of the article with the strict proviso that no changes or edits are made and the original work is properly cited (including links to both the formal publication through the relevant DOI and the license). See: https://creativecommons.org/licenses/by-nc-nd/4.0/.

\section{References}

1. Panoulas VF, Francis DP, Ruparelia N, et al. Femalespecific survival advantage from transcatheter aortic valve implantation over surgical aortic valve replacement: Meta-analysis of the gender subgroups of randomised controlled trials including 3758 patients. Int J Cardiol 2018;250:66-72.

2. Van Hemelrijck M, Taramasso M, De Carlo C, et al. Recent advances in understanding and managing aortic stenosis. F1000Res 2018;7:58.

3. Vandvik PO, Otto CM, Siemieniuk RA, et al. Transcatheter or surgical aortic valve replacement for patients with severe, symptomatic, aortic stenosis at low to intermediate surgical risk: a clinical practice guideline. BMJ 2016;354:15085.

4. Lederman RJ, Babaliaros VC, Greenbaum AB. How to perform transcaval access and closure for transcatheter aortic valve implantation. Catheter Cardiovasc Interv 2015;86:1242-54.

5. Watson DR, Yakubov SJ, Lyons JM, et al. Trans-subclavian approach for transcatheter aortic valve replacement. Ann Cardiothorac Surg 2017;6:565-7.

6. Overtchouk P, Alqdeimat I, Coisne A, et al. Transcarotid approach for TAVI: an optimal alternative to the transfemoral gold standard. Ann Cardiothorac Surg 2017;6:555-7.

7. Williams M, Kodali SK, Hahn RT, et al. Sex-related differences in outcomes after transcatheter or surgical aortic valve replacement in patients with severe aortic stenosis: Insights from the PARTNER Trial (Placement of Aortic Transcatheter Valve). J Am Coll Cardiol 2014;63:1522-8.

8. Onorati F, D'Errigo P, Barbanti M, et al. Different 
impact of sex on baseline characteristics and major periprocedural outcomes of transcatheter and surgical aortic valve interventions: Results of the multicenter Italian OBSERVANT Registry. J Thorac Cardiovasc Surg 2014;147:1529-39.

9. Skelding KA, Yakubov SJ, Kleiman NS, et al. Transcatheter Aortic Valve Replacement Versus Surgery in Women at High Risk for Surgical Aortic Valve Replacement (from the CoreValve US High Risk Pivotal Trial). Am J Cardiol 2016;118:560-6.

10. Ghare MI, Chandrasekhar J, Mehran R, et al. Sex Disparities in Cardiovascular Device Evaluations: Strategies for Recruitment and Retention of Female Patients in Clinical Device Trials. JACC Cardiovasc Interv 2019;12:301-8.

11. Mack MJ, Leon MB, Thourani VH, et al. Transcatheter Aortic-Valve Replacement with a Balloon-Expandable Valve in Low-Risk Patients. N Engl J Med 2019;380:1695-705.

12. Popma JJ, Deeb GM, Yakubov SJ, et al. Transcatheter Aortic-Valve Replacement with a Self-Expanding Valve in Low-Risk Patients. N Engl J Med 2019;380:1706-15.

13. Carroll JD, Carroll EP, Feldman T, et al. Sex-associated differences in left ventricular function in aortic stenosis of the elderly. Circulation 1992;86:1099-107.

14. Bagienski M, Tokarek T, Wiktorowicz A, et al. Sex-related differences in clinical outcomes and quality of life after transcatheter aortic valve implantation for severe aortic stenosis. Postepy Kardiol Interwencyjnej 2017;13:233-9.

15. Chaker Z, Badhwar V, Alqahtani F, et al. Sex Differences in the Utilization and Outcomes of Surgical Aortic Valve Replacement for Severe Aortic Stenosis. J Am Heart Assoc 2017;6.

16. López-de-Andrés A, Méndez-Bailón M, Perez-Farinos $\mathrm{N}$, et al. Gender differences in incidence and in-hospital outcomes of surgical aortic valve replacement in Spain, 2001-2015. Eur J Public Health 2019;29:674-80.

17. Elhmidi Y, Piazza N, Mazzitelli D, et al. Sex-related differences in 2197 patients undergoing isolated surgical aortic valve replacement. J Card Surg 2014;29:772-8.

18. Wong SC, Yeo I, Bergman G, et al. The Influence of Gender on In-Hospital Clinical Outcome Following Isolated Mitral or Aortic Heart Valve Surgery. Cardiovasc Revasc Med 2019;20:468-74.

19. Hayashida K, Morice MC, Chevalier B, et al. Sex-related differences in clinical presentation and outcome of transcatheter aortic valve implantation for severe aortic stenosis. J Am Coll Cardiol 2012;59:566-71.
20. Humphries KH, Toggweiler S, Rodes-Cabau J, et al. Sex differences in mortality after transcatheter aortic valve replacement for severe aortic stenosis. J Am Coll Cardiol 2012;60:882-6.

21. O'Connor SA, Morice MC, Gilard M, et al. Revisiting Sex Equality With Transcatheter Aortic Valve Replacement Outcomes: A Collaborative, Patient-Level Meta-Analysis of 11,310 Patients. J Am Coll Cardiol 2015;66:221-8.

22. Saad M, Nairooz R, Pothineni NVK, et al. Long-Term Outcomes With Transcatheter Aortic Valve Replacement in Women Compared With Men: Evidence From a MetaAnalysis. JACC Cardiovasc Interv 2018;11:24-35.

23. Chandrasekhar J, Dangas G, Yu J, et al. Sex-Based Differences in Outcomes With Transcatheter Aortic Valve Therapy: TVT Registry From 2011 to 2014. J Am Coll Cardiol 2016;68:2733-44.

24. Chieffo A, Petronio AS, Mehilli J, et al. Acute and 30Day Outcomes in Women After TAVR: Results From the WIN-TAVI (Women's INternational Transcatheter Aortic Valve Implantation) Real-World Registry. JACC Cardiovasc Interv 2016;9:1589-600.

25. Chieffo A, Petronio AS, Mehilli J, et al. 1-Year Clinical Outcomes in Women After Transcatheter Aortic Valve Replacement: Results From the First WIN-TAVI Registry. JACC Cardiovasc Interv 2018;11:1-12.

26. Benjamin EJ, Blaha MJ, Chiuve SE, et al. Heart Disease and Stroke Statistics-2017 Update: A Report From the American Heart Association. Circulation 2017;135:e146-e603.

27. Bach DS, Radeva JI, Birnbaum HG, et al. Prevalence, referral patterns, testing, and surgery in aortic valve disease: leaving women and elderly patients behind? J Heart Valve Dis 2007;16:362-9.

28. Mohr FW, Holzhey D, Mollmann H, et al. The German Aortic Valve Registry: 1-year results from 13,680 patients with aortic valve disease. Eur J Cardiothorac Surg 2014;46:808-16.

29. Pacheco C, Henri C, Forcillo J, et al. Transcatheter Aortic Valve Replacement for Severe Aortic Stenosis in Women: Clinical Characteristics and Outcomes. Can J Cardiol 2018;34:422-8.

30. Dobson LE, Fairbairn TA, Plein S, et al. Sex Differences in Aortic Stenosis and Outcome Following Surgical and Transcatheter Aortic Valve Replacement. J Womens Health (Larchmt) 2015;24:986-95.

31. Al-Lamee R, Broyd C, Parker J, et al. Influence of gender on clinical outcomes following transcatheter aortic valve implantation from the UK transcatheter aortic 
valve implantation registry and the National Institute for Cardiovascular Outcomes Research. Am J Cardiol 2014;113:522-8.

32. Joseph J, Naqvi SY, Giri J, et al. Aortic Stenosis: Pathophysiology, Diagnosis, and Therapy. Am J Med 2017;130:253-63.

33. Iung B, Cachier A, Baron G, et al. Decision-making in elderly patients with severe aortic stenosis: why are so many denied surgery? Eur Heart J 2005;26:2714-20.

34. Duncan AI, Lin J, Koch CG, et al. The impact of gender on in-hospital mortality and morbidity after isolated aortic valve replacement. Anesth Analg 2006;103:800-8.

35. Kalavrouziotis D, Rodes-Cabau J, Bagur R, et al.

Cite this article as: Caponcello MG, Banderas LM, Ferrero C, Bramlage C, Thoenes M, Bramlage P. Gender differences in aortic valve replacement: is surgical aortic valve replacement riskier and transcatheter aortic valve replacement safer in women than in men? J Thorac Dis 2020;12(7):3737-3746. doi: $10.21037 /$ jtd-20-700
Transcatheter aortic valve implantation in patients with severe aortic stenosis and small aortic annulus. J Am Coll Cardiol 2011;58:1016-24.

36. Voigtlander L, Seiffert M. Expanding TAVI to Low and Intermediate Risk Patients. Front Cardiovasc Med 2018;5:92.

37. Rogers T, Thourani VH, Waksman R. Transcatheter Aortic Valve Replacement in Intermediate- and Low-Risk Patients. J Am Heart Assoc 2018;7.

38. Mihos CG, Klassen SL, Yucel E. Sex-Specific Considerations in Women with Aortic Stenosis and Outcomes After Transcatheter Aortic Valve Replacement. Curr Treat Options Cardiovasc Med 2018;20:52. 